\title{
Intensive Teacher Education for an EMI Context: Facilitating the Professional Development of University Teachers
}

\author{
Simon Webster ${ }^{1} \&$ Rupert Herington ${ }^{1}$ \\ ${ }^{1}$ Language Centre, University of Leeds, UK \\ Correspondence: Simon Webster, Lecturer, Language Centre, University of Leeds, UK.
}

Received: July 26, 2021

Accepted: August 13, 2021

Online Published: August 27, 2021

doi:10.5430/irhe.v6n3p1

URL: https://doi.org/10.5430/irhe.v6n3p1

\begin{abstract}
In this paper we report on an intensive professional development intervention (PDI) delivered in a UK higher education setting for university teachers from different countries. These teachers were either teaching, or preparing to teach, English Medium Instruction (EMI) courses in a range of disciplines. Few previous studies have focussed on the impact of intensive training interventions on teacher participants, particularly for interventions conducted outside teachers' local contexts. To address this, qualitative research was conducted that explores the influence of the PDI on participant teachers' beliefs and self-reported teaching practices in their own institutional contexts. The findings suggest that the PDI resulted in significant changes in many of the participants' beliefs about teaching pedagogy for an EMI context. The PDI also appeared to increase teachers' self-efficacy, and to facilitate innovation in their classroom practices. As a result, the study highlights the pedagogical elements of the PDI which emerged as being significant in bringing about these changes and discusses the implications for PDI design. Overall, the study suggests the potential role that intensive PDIs delivered outside teachers' home and national contexts can play in facilitating teacher development.
\end{abstract}

Keywords: teacher education, professional development, short courses, teacher beliefs, PDI, EMI

\section{Context}

Universities in many non-majority English-speaking countries are offering an increasing number of English Medium Instruction (EMI) courses, where subject-specific courses are taught through the medium of English (Macaro et al., 2018; Wächter \& Maiworm, 2014). In recent years, this trend of EMI courses being offered in a wide range of subject specialisms has become particularly evident in East Asian countries such as Japan and South Korea (Rose \& McKinley, 2018). The transition to EMI teaching for university teachers accustomed to teaching in L1 medium of instruction can present significant classroom challenges for these subject specialists (Lasagabaster, 2018). Many universities offer training and on-going in-house support (see, for example, Dafouz, 2018) and in certain contexts, faculty are required to undertake a certification course before teaching EMI courses (Dubow \& Gundermann, 2017; Macaro et al., 2020). Despite this, however, teaching faculty who are required to teach EMI courses may not have received any formal training in how to teach their subject through the medium of English (see Guarda \& Helm, 2017; Leong, 2017; O'Dowd, 2018). Where the capacity does not exist to provide such training locally, external EMI training and support may be required. This paper reports on the results of a study exploring the impact on teaching beliefs and practices of a short, intensive professional development intervention (PDI) delivered outside the teachers' home institutions and national contexts.

\section{Literature}

\subsection{Teacher Development}

The literature on EMI teacher development is extremely limited (Macaro, 2018; Macaro et al., 2018). Teacher development research in general education, however, provides useful insights into how EMI teacher development might be conceived. Stage theory (see, for example, Bullough \& Baughman, 1993; Fuller, 1969) represents an attempt to identify specific phases in the development of teaching expertise. As with Kember's (1997) categories for conceptions of teaching, and separate studies into the knowledge, skills and attitudes of expert teachers (e.g. Berliner, 1987; Forde \& McMahon, 2019), a progression is indicated from teacher-centredness and basic classroom management concerns to a greater emphasis on student learning and classroom dynamics which promote such learning (see also Boylan et al., 2018, for a summary of key professional development models). 
Teachers' beliefs play a central role in the development process, since teachers often hold preconceptions about learning and teaching which are resilient to change (Pajares, 1992). Engagement with teachers' deeply-held beliefs is therefore a pre-requisite for changes in their teaching practices to be facilitated (Richardson, 1996). The literature also indicates that teachers need to experiment with innovation in the practical, contextualised realities of their own classrooms in order for new practices to become routinized (see, for example, Baldwin \& Ford, 1988; Makopoulou et al., 2019). In his study of pedagogical development in EMI teachers, Farrell (2019) highlights the centrality of reflective practice in this process of establishing innovations in classroom practices. Research on EMI teachers by Tsui (2018) additionally stresses the importance of self-efficacy beliefs for teachers to be able to introduce innovation from teacher education courses in their own classrooms. Given such understandings of the necessary conditions for teacher development to take place, the question which is addressed in the present study is whether PDIs which take place over a short period of time can still impact on teachers' beliefs and practices.

\subsection{PDI Pedagogy}

There is a dearth of literature on appropriate pedagogy for PDIs targeted at EMI teachers. In the absence of such research, the pedagogical approach adopted tends to draw on the broader, teacher education pedagogy literature. Vygotsky's (1978) work, for example, promotes a focus on relationships in which facilitators engage participants in meaningful learning activities and support them in the development of their skills and conceptual understanding (see Oxford, 1997). The 'scaffolding' process then involves the withdrawal of this support once it is no longer required (Van de Pol et al., 2010) as a means of developing participants' self-efficacy and autonomous behaviour (Bandura, 1997). Collaborative learning has also been shown to play a significant role in facilitating teacher education participants' understanding through reflective discussions and providing a support community (Farrell, 2019).

Involving teachers in experiential learning during a PDI provides them with opportunities to observe innovative pedagogy in practice (see, for example, Cheng et al., 2010; Wallace, 1991). This first-hand experience of being taught through such approaches can contribute to changes in participants' beliefs (Kaufman, 1996; Tang et al., 2012). Opportunities for participants to subsequently experiment with modelled behaviours have been shown to play an important role in influencing future classroom practices (Ingvarson et al., 2005). However, this development is contingent on developmental courses including appropriate opportunities for reflection by the participants on their experiences (Girvan et al., 2016). Furthermore, research suggests that teachers' existing beliefs need to be explicitly addressed during such courses, as otherwise the hegemony of [existing] knowledge structures will remain unchallenged' (Tillema, 1995, p. 312). As the following section indicates, though, the processes described imply extended engagement with teachers that may not be possible with the duration of the PDI. Research on shorter interventions is therefore notably absent in the literature.

\subsection{PDI Context and Duration}

The PDI context is particularly significant for this study as the intervention took place outside the teachers' home institutions and in a different national setting. This geographical factor contrasts the dominant PDI model, in which training for EMI teachers takes place in the teachers' own professional contexts (see O'Dowd, 2018). Several studies have focused on the localized factors which can affect the introduction of classroom innovation (Bradford, 2016; Ödalen et al., 2019), and on the subsequent classroom experimentation in teachers' normal teaching contexts required for practical knowledge development to take place (Lauer et al., 2014; Zehetmeier et al., 2015). The literature also suggests possible rejection of innovation where participants perceive a lack of applicability to their local context or difficulties in the actual implementation of innovation in their home institutions (Holliday, 1992; Wedell \& Malderez, 2013; Le Fevre, 2014). A limitation of many externally-located courses is therefore that they take place 'without due consideration of the specific contexts in which teachers work' (Makopoulo et al., p. 2), and fail to engage the teachers in impactful professional learning.

Changes in teachers' pedagogical beliefs and the development of practices to suit the conditions of the home classroom appear to require substantial engagement (Garet et al., 2001). A recurrent concern about short teacher development courses in the general literature is, therefore, that such interventions do not facilitate teacher development support over an extended period (see, for example, Patton \& Parker, 2014). Postareff, Lindblom \& Nevgi (2007) concluded in their research, for example, that courses need to last at least a year to provide sufficient time for teacher development to take place. In contrast, Makopoulou et al. (2019) did, however, identify a degree of impact on participants' self-efficacy in their study of the impact of a short pedagogical training course for university teachers. In an EMI context, Guarda \& Helm's (2017) study of a short course also reported certain success in changing participants' beliefs and confidence with pedagogical innovation. Additionally, Klaassen \& De Graaff's (2001) study indicated increased classroom 
interaction by participants after an intervention lasting five half days. However, both they and Desimone \& Pak (2017) recommend prolonged engagement in PDI teacher education courses where this is possible.

Although the literature highlights limitations in the potential impact of short courses, there is a strong need for empirical research into the design and effectiveness of models of EMI teacher development (Macaro, 2018). Such research will provide a data-driven basis for future decision-making about EMI teacher education. This paper therefore aims to make a contribution to the field by exploring the impact of a short PDI designed for EMI teachers.

\section{Methodology}

\subsection{Professional Development Intervention}

The PDI in this study was a 5-day course (25 contact hours), which aimed to develop university teachers' ability to teach their respective subjects in an English medium instruction (EMI) context. It was developed in response to teacher development requests from several universities located in China, Japan and South Korea. Adopting a constructivist and experiential learning approach (Roberts, 2016), the course focused principally on the following three developmental areas: English language use in an EMI teaching context; planning \& classroom management; and communication skills. These course aims were based on the participants' self-stated needs and those identified with previous cohorts by the course designer. In the needs analysis conducted with the cohort for this study, most participants expressed an interest in active learning and in techniques to facilitate greater interaction in the EMI classroom.

The course design included opportunities for the participants to observe live lectures and seminars in their own broad subject areas, this enabled them to experience such delivery through the medium of English. Participants were encouraged during the course to reflect on their existing teaching and learning experiences, and to share ideas with other participants through pair and group discussion. They also experienced active learning first-hand as participants in trainer-led sessions, in addition to engaging in peer micro-teaching and the delivery of a 6-minute presentation in their respective subject areas. The tasks provided an opportunity for the participants to apply the pedagogical approaches presented on the course and to reflect on their experiences with peer and tutor feedback.

The study aimed to answer the following two research questions:

1. How did this short PDI impact on practitioners' beliefs about EMI teaching and their classroom practices?

2. What factors appear to have been significant in the impact of the PDI?

\subsection{Research Sample and Setting}

The professional development intervention was delivered at a UK university to university lecturers from several East Asian countries who were either currently teaching, or preparing to teach, degree subjects in the medium of English. The course participants were subject specialists in a wide range of disciplines. An invitation to participate in the research was sent to the full cohort of 26 participants 3 months after their attendance on the PDI. The data included in this study is from the seven participants who responded to the call to participate (six from Japan and one from South Korea), all of whom had a self-certified level of proficiency in English at B2 or above on the Common European Reference Framework. Most of them had not received formal teacher training, particularly in relation to EMI teaching.

\subsection{Data Collection}

This qualitative research (Mason, 2002) adopted an emic approach (Cohen et al., 2007) to explore the key issues by highlighting the participants' own perspectives on the impact of the PDI. Semi-structured individual interviews (Kvale \& Brinkmann, 2009) were adopted, as they offer the opportunity to probe, to clarify and to respond to participants' comments in a manner which allows for greater exploration of emerging themes during the interviews (Seidman, 2013). The interviews were designed to generate data in three broad areas: the participants' experiences of the PDI, any impact the intervention may have had on their beliefs, and any reported impact on their teaching practices. These in-depth interviews, each of approximately 40 minutes in duration, were conducted by one of the co-authors through a teleconferencing platform owing to geographical distances involved. Teleconferencing provided visual contact to facilitate rapport with the research participants (Drever, 2003). The data collection took place approximately three months after the end of the participants' attendance on the course, which allowed time for any teacher classroom experimentation and to thereby establish whether lasting impact had resulted from the intervention.

The study was carried out in full accordance with the ethical requirements of the home institution. Participants were provided with full details of the research, including their right to withdraw at any point, the security arrangements for data collection and storage, and a guarantee of anonymity in research outputs. Informed consent (Denzin \& Lincoln, 2000) was obtained from all the participants prior to data collection taking place. 


\subsection{Data Analysis}

The audio-recordings were transcribed professionally and reviewed for accuracy by the researchers. A thematic analysis approach was then adopted to the data analysis (Braun \& Clark, 2006). The two researchers first engaged in repeated readings of the data in order to familiarise themselves with the content and to develop an initial understanding of possible patterns (Terry et al., 2017). In order to increase the trustworthiness of the research (Lincoln \& Guba, 1985), significant sections of the data were then coded independently by the co-researchers. On the basis of this initial inductive analysis, parent nodes were jointly agreed for the data to then be re-coded using commercial software. Following the completion of the coding process, the researchers began to identify themes from the coded extracts. This was an iterative process (Kennedy, 2018) in which emerging themes were refined, combined and, at times, rejected where there was insufficient data for the theme to be developed. Repeated co-researcher debriefing contributed to this depth of engagement with the data (Cutcliffe \& McKenna, 1999), which in turn is a contributing factor to research trustworthiness (Nowell et al., 2017).

\section{Findings}

The findings are presented here according to the three central themes which emerged from the data: changes in participants' beliefs about teaching and learning; changes in their reported teaching practices; and their reports of self-efficacy in relation to teaching innovation. Substantial interview extracts are included with the aim of allowing readers to familiarise themselves with the participants' perspectives first-hand (Cohen et al. 2007), whilst the authors' interpretations of their significance also provide a narrative (Braun \& Clarke, 2006). To preserve participant anonymity, the source of each participant data extract is indicated by a code (P1-P7).

\subsection{Changes in Participants' Beliefs About Teaching and Learning}

The findings indicate that the PDI resulted in significant changes in how three of the seven participants viewed EMI teaching. The following extract provides an indication of the impact that the introduction to participatory pedagogy had on the two participants unfamiliar with such a teaching approach:

When I was a student, the teacher at the university gave me a lecture. Not necessarily active learning stuff. So, I thought the teaching... the teaching is a lecture. But throughout the course, I learnt that teaching is not really like teaching the lecture of something, but more understanding or like... actually, you can do something with those things, rather than just the giving of information [...] You know it's not group discussion or active learning or those things. (P6)

All but one of the participants contrasted the teaching on the PDI with the teaching cultures in their home contexts. In the following extract, a participant discusses this contrast in relation to student engagement:

It was a very good opportunity to learn the... how to organise a lecture. The lecture which you need to engaging students. Yeah, it will be one of the features of the lectures in Japan, to read and not so many lecturers are trying to engage the students in involving them in discussion and other things. (P5)

Increased understanding of student-centred classrooms and a corresponding desire to introduce classroom innovations in their own teaching contexts could be identified for three of the participants. This is seen in the example below:

From the way you are teaching, probably I shouldn't have all the answers basically. So, I should involve the students in the conversation and getting them to give feedback in the lecture. So, I don't have to... A lot of information can come from anywhere. So, I should trust the students more and give them more opportunities to enrich the class with their information and knowledge. (P2)

An increased commitment to active learning pedagogies and a stronger awareness of the importance of teacher-student interaction can also be seen in the following extract from the same participant. He attributes this development to the experiential learning on the PDI:

Because we were students, I learnt from you how to give clear instructions. So, I guess I should... when I'm teaching, I should be picking things up from the students. For example, I remember you gave us a picture and then were like... just to give instructions on how to start. So, I would probably... if I hadn't taken the course, I would take that as something that is obvious and ask students to start working on things right away, but I realise that if you don't give clear instruction, you will get different answers from the students [...] I think from their perspective. (P2) 
The PDI also had the effect of confirming and strengthening the existing beliefs of the five participants who had already recognised the pedagogical limitations of teaching in their own institutional contexts. One of them explains his experience as follows, highlighting the significance of the change of environment:

Around me there are so many professors who still sticks on the methodology of teaching, only focussing on transferring knowledge and they believe a large amount of knowledge could be more valuable. But I didn't think so, but joining your course and taking your lecture, I thought my idea... this should be, I don't know if I can say correct or not but not out of the point. Yeah. So, I have begun to have confidence about my belief, so I came to this conclusion with the transition of environment. (P5)

A similar sentiment was expressed by another participant who, when asked about changes in his beliefs about teaching, explained the following:

To be honest with you it hasn't changed. But I'm more convinced that my thinking was not wrong because I became a university professor just one year ago. Before that, I was in business. So, in the business written communication is more important. So, I have a certain idea and idealistic thought and, after participating in your course, my thought was not wrong. (P3)

The change of environment provided by the PDI was referred to explicitly by three of the participants; being out-of-country could be seen to allow clear comparisons to be made between the PDI context and participants' own teaching environments. One participant, for example, responded very positively to being offered praise on the programme. He explained that such feedback was uncommon in his own institutional context and that his on-course experience had made him aware of the importance of the learners' affective domain:

For example, when in mock lecture, and after, of course, after you evaluate me, and in the evaluation, you always give me feedback and that very encouraged me. But in Japan we evaluate more strictly, probably because there is, you know, in class examination system in Japan that is taught with the university exam and high school exam, and that's all. So, many high school or junior high school students try to enter a higher university. And in the course, students are evaluated by best points very strictly. So, they are accustomed to be evaluated by points, and teachers also tend to evaluate in such a way. So, very not so often to praise and that is very new for me. And after that, I try to praise my students. (P4)

This direct experience of active learning was identified by three of the course participants as reinforcing existing beliefs that such a pedagogical approach was required in their own contexts. One of them explained his view as follows:

[The course] actually confirmed my belief that the student-centred learning... because your workshop was based on the discussions and practices by participants... so it was very helpful to experience all the activities instead of just sitting and listening to the lectures. So, I... yeah, strongly... I already believed that student centred learning and teaching is pretty good, but I value the student-centred learning more this semester. (P7)

The strong impact of experiential learning on the PDI is also evident in comments made by a second participant:

Well, to be honest with you, conceptually the course was exactly what I expected. So, conceptually there aren't much new, really. But as an actual experience, that was new. Theory and practice are rather different. Taking part is very useful. (P3)

The following section explores the extent to which these changes in the teachers' beliefs translated into classroom innovation.

\subsection{Changes in Participants' Reported Teaching Practices}

All participants reported the direct importation into their classrooms of teaching techniques that they had themselves experienced as participants on the PDI. Here, one of them describes an example of active learning he had incorporated into his regular teaching practices:

The biggest change, as I've mentioned before, is that I have decided to change my lectures into quiz first and then information. I think it's really made things easy, and also the students don't sleep in class. I point at them, 'Okay, you! Answer this question. Even if you don't know the answer then just tell us anything.' That's really changed the class that I taught. I think that's what I'll use in... 
because most of my lectures are in the fall. I will use that technique and make sure that the students know this is the standard. (P2)

Another participant reported on changes to his use of group work as a result of experiential learning on the PDI:

I think that I like the strategy of chatting with the students. Firstly, you have made us in five groups. Then at the beginning of the class... then in the middle of the class, you allocated to us a number one, two, three, four, five... yeah, to change the group. Actually, after that I used that strategy a couple of times. Yeah. (P5)

There were very limited references to language development in the data, but one of the participants commented that she had found the review of lecture-related language on the PDI useful for her own teaching:

[The class] was about lecturer language - how we organised the whole lecture, and then what kind of, like, lecturer language that we can use. It's very helpful for me to think about and, like, review because usually the lecturers in South Korea, even though they study abroad for their studies or their research... so their English is not that bad, but they really didn't know which expression exactly and what kind of structure they have to organise for their EMI. (P7)

This participant also indicated that such language development and the introduction of signposting and checking of student understanding in her classroom teaching were related:

I realised that using more signposting and micro-language would be more helpful for my students to follow my lecture. So, after that workshop, I actually used like more lecture language, and also, I kind of, like, check my students' understanding, I think, more often than before. (P7)

One of the participants also reported on the positive effect on student engagement that she had witnessed from introducing signposting in her classroom teaching after the PDI:

They look at me after I start teaching. Usually in Japan, Japanese says to just start doing lectures, just do start the contents of the lecture. But I give them that, 'Today, we are going to do this, and you have to learn two things - this one and this one. So, please focus on those key words.' Something like that. So, they just started taking notes. I realised clearly that the atmosphere in the classroom changes from the previous one. (P1)

The impact of the PDI was not limited to instances where teaching strategies were new to participants. The three participants already familiar with the teaching techniques presented on the PDI all reported an attitudinal change and more consistent adoption of the teaching techniques following the intervention:

That was really... because somehow, unconsciously I used to try and do that, but after the information that you gave us, then I tried to consciously put that in to my lectures, and it's really very helpful, in that I can see the students understanding content more. (P2)

The practical nature of the PDI appeared to be a particularly significant factor in facilitating one participant's introduction of classroom innovations. Here, she emphasises the value of practical techniques for immediate classroom implementation:

I also... at a conference about active learning in America... after the conference, I was not very much comfortable, because all those teaching at undergraduate level in America... I felt like it was a show. So, I was not very much comfortable, and some of them I thought do not fit in a Japanese classroom. But what I learned in [university where the PDI took place] was more focused around the teaching... a specialised field, and I can do and use it instantly soon after the seminar. So, it was very good for me. (P1)

The findings also indicated that this teacher went beyond the introduction of discrete teaching techniques and incorporated classroom management sequences designed to increase student engagement and participation. She explained one such innovation she had introduced as follows:

In the lecture, I stopped teaching them and started looking for answers, and I did not tell them how I feel until very last, and let them talk, and everybody talked: 'How about you? How about you in your country?' And they started doing and arguing with each other, and talking... and, after the discussion, then I summarise it. Then, I give another explanation and also the suggestions, so that I could conclude the class more and I could let them talk, and not only learning, but I could let them discuss by themselves. I gave them the motivation and also the freedom to talk. (P1) 
In addition, there was an instance of one teacher introducing classroom innovations that were individual and creative responses to his own teaching context. Reporting on a science lesson, the participant provided the following example of how he had introduced more active learning:

I tried to make it engaging for the students, and if I didn't have that course... your course, I would have given the usual lecture. But I was trying to make it a little bit interactive. So, I gave some questions to them, like some pop quiz kind of questions, and also, I brought the microscope and showed them the live worms to make it kind of real for them. (P6)

Three of the course participants also reported on factors which constrained the introduction of innovations in their own teaching contexts. These included collegial resistance to change and opposition by students accustomed to existing modes of interaction. One of the several teachers who reported introducing pair work as a result of the PDI also highlighted the implications of the limited teaching time available. In the interview extract below, however, it can be seen that he managed to adapt the pair work to the local teaching context:

Unfortunately, I only have 90 minutes on this course, so time is scarce. Time is precious, so I ask them to do... after the class, I give them homework: 'Pick up one company', for example. I don't know... British company, Glaxo or Unilever. Analyse the company comparing with a Japanese company, and how it is different from a Japanese company, and that's with your pair, and make a presentation jointly in the next class. It started lowering the hurdle for them, and they are not as stressed as if they do it alone. (P3)

\subsection{Participants' Self-Efficacy}

Many of the participants commented on the confidence that they had gained in their own teaching abilities on the PDI, and indicated that this increased self-efficacy had enabled the classroom innovation described above to take place. The teachers noted, for example, that they felt the guidance that they had received prepared them to respond appropriately to classroom situations. As one participant explains:

When I started teaching in English, because I told you, I have never learned and studied in a foreign language. So, I could do the conversation, but I was not very certain about my level of academic teaching. But this seminar gave me the confidence and guidance how to direct and how to react to the students. I was not scared as much. (P1)

Two of the participants also specifically reported that they benefitted from the opportunity to practise teaching techniques in micro-teaching sessions. The first of these two participants put it as follows:

I'm not nervous and that's what I should expect in a real class, but I think it was pretty real for me, although it's not a real class. I didn't have a chance to teach beforehand. So, that's why that nervousness really helped me to give a presentation in a real way, because even if I practiced by myself, probably I can't get nervousness. (P6)

The same two participants also commented positively on the opportunity to receive feedback from teacher educators and other participants in order to evaluate their own performance and identify areas for development. As the second participant states:

So, during the second lecture, I really got very good feedback from the teachers, and also from the others in the class, and I think it's really helpful. (P2)

Two of the participants also commented that they placed a high value on the opportunity to observe other course participants regarded as dealing with similar teaching challenges. They believed that they had been able to develop their pedagogical understandings through the sharing of perspectives. One of them explained this in the following way:

Having the discussion with people from Nagoya, Korea and China, and realising that they have same kind of issue, same kind of problem, and same kind of ambition. That was a good experience to know that someone is thinking like me. (P3)

Almost half of the teachers also reported that their confidence increased and that they were encouraged to continue with innovations as a result of the positive and unexpected student response to the teaching innovations they had introduced post-PDI. The account by participant six is particularly revealing:

I saw some excited faces and some people were very responsive. I got a lot of questions, even from high school students. So, I think that was the best thing for me, because I didn't really expect the high school students to ask questions in English. It's pretty challenging in Japan. They're shy. 
Usually, they kind of hesitate to ask some questions, but I think they are trying to and then they actually asked many questions to me, and that was really amazing to me. (P6)

\section{Discussion}

\subsection{Teacher Development}

The findings suggest that quite significant teacher development took place overall as a result of this short, intensive, out-of-country PDI. Although the participants were impacted in diverse ways, three months after the PDI, almost half of them reported a notable and consistent change in their teaching beliefs as a result of the programme. In a similar number of instances, participants' positive beliefs regarding the teaching approaches advocated on the PDI were seen to be accompanied by an increased desire to introduce innovations in their own classrooms. Following Kember's (1997) teacher development model, a transition can be identified in most of the cases from a perception of teaching as information-presentation to the adoption of more student-centred beliefs in which the teacher's role is to facilitate understanding. That this self-reported teacher belief change and increased motivation to innovate should be brought about by a short (25-hour) intensive programme stands in sharp contrast to research indicating the need for prolonged engagement to facilitate such change (e.g. Desimone \& Pak, 2017; Garet et al., 2001; Klassen \& De Graaf, 2001).

For PDIs to improve learning outcomes, it is clearly necessary that belief change is accompanied by changes in classroom practices. All the participants in the study self-reported that they had subsequently introduced specific PDI course elements into their practices, and that these innovations had become broadly routinised. These findings suggest that certain teaching techniques could be readily incorporated into teachers' repertoires. For the three teachers already familiar with the teaching approach introduced on the PDI, their experience on the course led to the approach being employed more consistently. The significance here lies in the fact that the PDI provided the means by which participants' pedagogical beliefs were not only strengthened but were then put into practice. Moreover, two of the participants subsequently innovated beyond the specific teaching techniques introduced on the PDI with activities based on their broad understanding of active learning. In addition, several of the practitioners reported increased self-efficacy in conducting more student-centred teaching as a result of the PDI. Thus, participants appeared to be motivated to develop their practices according to the principles of active learning which they had assimilated, and felt able to implement these limited changes independently post-PDI.

\subsection{The PDI Course Design}

The data indicates that the design of the PDI was highly significant in bringing about the teacher development described above. Participants not only became aware of active learning techniques as received knowledge on the PDI, but saw the techniques skilfully modelled. A number of the participants reported how they had incorporated active learning into their own taught sessions as a result. For example, in the case of participant seven, such experiential learning was contrasted with her previous, more abstract, understanding of good practice in that it motivated her to change her own teaching practices. Hence, the modelling appears to have assisted participants in the setting up and management of activities, whilst the direct experience of the active learning techniques created an affective shift. Nearly half of the participants reported a reinforced belief that pedagogical change was required in their own contexts. The 'pedagogy in action' of the active learning teaching approach adopted on the PDI appears to have contributed significantly to this development.

Participants responded very positively to the experimentation with practical teaching techniques, which could then be introduced in their own teaching as low-risk innovations. The experience of this pedagogical change, however, appeared to be two-fold: firstly, the participants had, symbolically, begun the process of innovation, which they reported as being personally satisfying. In addition, the experience of the positive student response and increased engagement and learning referred to in three of the cases appeared to motivate the teachers to continue with the innovations. Indeed, in two cases, participants innovated beyond the simple reproduction of techniques introduced on the PDI. Participants' increased belief in the teaching approaches appeared to contribute to their desire to adopt creative responses to the subject content and to their home institutional settings. The positive student response to the introduction of specific teaching techniques may well have encouraged (and provided the self-efficacy necessary for) this more autonomous, contextualised development.

Participants' opportunity on the PDI to deliver talks in a scaffolded setting also appeared to be significant in determining impact. Two participants explicitly commented on the benefits of engaging in supported teaching and receiving feedback from teacher educators and other participants. This supportive environment in which to rehearse active learning approaches appears to have provided all participants with increased self-efficacy, which contributed to the introduction of innovation in their own institutional contexts following the PDI. 


\subsection{The PDI Location}

This teacher development took place outside the teachers' institutional and national contexts; it thereby removed the opportunity for on-course experimentation in teachers' habitual teaching settings, which is common to most EMI teacher education programmes (O'Dowd, 2018). However, the change of physical environment resulting from an out-of-country PDI appeared to provide most of the participants with valuable space and distance to reflect on their teaching approaches and compare their home institutional culture with that of the PDI setting. Indeed, in five of the cases, teachers found their existing concerns about pedagogy in their home contexts to be confirmed by the input from this new environment, and their personal investment to introduce innovation appeared to increase. Furthermore, participants commented favourably on the ability to share experiences with peers from a range of educational institutions, including those from other national contexts. This may have created the level of engagement necessary to facilitate belief change. Hence, it appears that for the participants in this study, the delivery location was beneficial rather than its constituting a constraint.

\section{Conclusion}

The limitations of sample size in this small-scale research need to be acknowledged. As a result, the findings here are not presented as being either reproducible or generalizable, but as illustrative of the potential benefits of this type of intervention. The research also generated data for participants' reported classroom practices without classroom observation data. The data for the effectiveness of the teachers' innovations in increasing student learning is therefore limited. Additionally, it is also recognised that the research sample was self-selecting, and that it may consist of those participants who were most predisposed to change in their pedagogical beliefs and practices.

Overall, however, the findings still suggest that an intensive PDI does have the potential to impact on teachers' beliefs and self-efficacy, which can then facilitate classroom innovation. Practitioners indicated that not only did they develop their understandings of active learning, but that they felt empowered to introduce specific PDI elements and to develop their own initiatives based on the concept of active learning. These impacts were attributed to the PDI course design and, in particular, to the experiential, scaffolded, collaborative and practical approach that it adopted. Whilst longer courses with more contact time offer greater opportunity for change to take place, the findings suggest that the design principles introduced may allow for teacher development to occur even on relatively short PDIs. In addition, one advantage of the change of institutional context may be precisely that it relocates the practitioner to a more creative space in which to explore concepts and to reflect on current practices in a fresh, supportive environment. Given the limited number of institutions with the capacity to provide in-house support (Macaro, 2020), the implications of this research include the role that this PDI model can potentially play either as a substitute for, or to complement, in-house EMI teacher education provision.

\section{References}

Baldwin, T. T., \& Ford, J. K. (1988). Transfer of training: A review and directions for future research. Personnel Psychology, 41(1), 63-10. https://doi.org/10.1111/j.1744-6570.1988.tb00632.x

Bandura, A. (1997). Self-efficacy: The Exercise of Control. Worth Publishers.

Berliner, D. (1987). Ways of thinking about students and classrooms by more and less experienced teachers. In J. Calderhead (Ed.), Exploring Teachers' Thinking (pp. 60-84). Cassell.

Boylan, M., Coldwell, M., Maxwell, B., \& Jordan, J. (2018). Rethinking models of professional learning as tools: A conceptual analysis to inform research and practice. Professional Development in Education, 44(1), 120-139. https://doi.org/10.1080/19415257.2017.1306789

Bradford, A. (2016). Toward a typology of implementation challenges facing English-medium instruction in higher education: Evidence from Japan. Journal of Studies in International Education, 20(4), 339-356. https://doi.org/10.1177/1028315316647165

Braun, V., \& Clarke, V. (2006). Using thematic analysis in psychology. Qualitative Research in Psychology, 3(2), 77-101. https://doi.org/10.1191/1478088706qp063oa

Bullough, R., \& Baughman, K. (1993). Continuity and change in teacher development: a first year teacher after five years. Journal of Teacher Education, 44(2), 86-99. https://doi.org/10.1177/0022487193044002003

Cheng, M. M., Cheng, A. Y., \& Tang, S. Y. (2010). Closing the gap between the theory and practice of teaching: Implications for teacher education programmes in Hong Kong. Journal of Education for Teaching, 36(1), 91-104. https://doi.org/10.1080/02607470903462222 
Cohen, M., Manion, L., \& Morrison, K. (2007). Research Methods in Education (6th ed.). Routledge.

Cutcliffe, J. R., \& McKenna, H. (1999). Establishing the credibility of qualitative research findings: The plot thickens. Journal of Advanced Nursing, 30(2), 374-380. https://doi.org/10.1046/j.1365-2648.1999.01090.x

Dafouz, E. (2018). English-medium instruction and teacher education programmes in higher education: ideological forces and imagined identities at work. International Journal of Bilingual Education, 21(5), 540-552. https://doi.org/10.1080/13670050.2018.1487926

Denzin, N., \& Lincoln, Y. (2000). Handbook of Qualitative Research. Sage.

Desimone, L. M., \& Pak, K. (2017). Instructional coaching as high-quality professional development. Theory into Practice, 56(1), 3-12. https://doi.org/10.1080/00405841.2016.1241947

Drever, E. (2003). Using Semi-structured Interviews. SCRE, University of Glasgow.

Dubow, G., \& Gundermann, S. (2017). Certifying the linguistic and communicative competencies of teachers in English-medium instruction programmes. Language Learning in Higher Education, 7(2), 475-487. https://doi.org/10.1515/cercles-2017-0021

Farrell, T. S. C. (2019). Professional development through reflective practice for English-medium instruction (EMI) teachers. International Journal of Bilingual Education and Bilingualism, 1-10. https://doi.org10.1080/13670050.2019.1612840

Forde, C., \& McMahon, M. (2019). Issues of teacher expertise and teacher quality. Palgrave Macmillan.

Fuller, F. (1969). Concerns of teachers: A developmental conceptualization. American Educational Research Journal, 6(2), 207-226. https://doi.org/10.3102/00028312006002207

Garet, M. S., Porter, A. C., Desimone, L., Birman, B. F., \& Yoon, K. S. J. (2001). What makes professional development effective? Results from a national sample of teachers. American Educational Research Journal, 38(4), 915-945. https://doi.org/10.3102/00028312038004915

Girvan, C., Conneely, C., \& Tangney, B. (2016). Extending experiential learning in teacher professional development. Teaching and Teacher Education, (58), 129-139. https://doi.org/10.1016/j.tate.2016.04.009

Guarda, M., \& Helm, F. (2017). 'I have discovered new teaching pathways': The link between language shift and teaching practice. International Journal of Bilingual Education and Bilingualism, 20(7), 897-913. https://doi.org/10.1080/13670050.2015.1125848

Holliday, A. (1992). Tissue rejection and informal order in ELT projects. Applied Linguistics, 13(4), $403-424$. https://doi.org/10.1093/applin/13.4.403

Ingvarson, L., Meiers, M., \& Beavis, A. (2005). Factors affecting the impact of professional development programs on teachers' knowledge, practice, student outcomes \& efficacy. Education Policy Analysis Archives 13(10), 10-26. https://doi.org/10.14507/epaa.v13n10.2005

Kaufman, D. (1996). Constructivist-based experiential learning in teacher education. Action in Teacher Education, 18(2), 40-50. https://doi.org/10.1080/01626620.1996.10462832

Kelle, U. (2014). Theorization from data. In F. Uwe (Ed.), The SAGE handbook of qualitative data analysis (pp. 554-568). Sage.

Kember, D. (1997). A reconceptualisation of the research into university academics' conceptions of teaching. Learning Instruction, 7(3), 255-275. https://doi.org/10.1016/S0959-4752(96)00028-X

Kennedy, B. (2018). Deduction, induction and abduction. In F. Uwe (Ed.), The SAGE Handbook of Qualitative Data Collection (pp. 49-64). Sage.

King, N. (2004). Using interviews in qualitative research. In C. Cassell., \& G. Symon (Eds.), Essential Guide to Qualitative Methods in Organizational Research (pp. 11-22). Sage.

Klaassen, R. G., \& De Graaff, E. (2001). Facing innovation: Preparing lecturers for English-medium instruction in a non-native context. European Journal of Engineering Education, 26(3), 281-289. https://doi.org/10.1080/03043790110054409

Kvale, S., \& Brinkmann, S. (2009). Interviews: Learning the Craft of Qualitative Research Interviewing. Sage.

Lasagabaster, D. (2018). Fostering team teaching: Mapping out a research agenda for English-medium instruction at university level. Language Teaching, 51(3), 400-416. https://doi.org/10.1017/S0261444818000113 
Lauer, P. A., Christopher, D. E., Firpo-Triplett, R., \& Buchting, F. (2014). The impact of short-term professional development on participant outcomes: A review of the literature. Professional Development in Education, 40(2), 207-227. https://doi.org/10.1080/19415257.2013.776619

Leong, P. (2017). English-medium instruction in Japanese universities: Policy implementation and constraints. Current Issues in Language Planning, 18(1), 57-67. https://doi.org/10.1080/14664208.2016.1204053

Macaro, E. (2018). English medium instruction: content and language in policy and practice. Oxford: Oxford University Press.

Macaro, E., Akincioglu, M., \& Han, S. (2020). English medium instruction in higher education: Teacher perspectives on professional development and certification. International Journal of Applied Linguistics, 30(1), 144-157. https://doi.org/10.1111/ijal.12272

Macaro, E., Curle, S., Pun, J., An, J., \& Dearden, J. (2018). A systematic review of English medium instruction in higher education. Language Teaching, 51(1), 36-76. https:// doi.org/10.1017/S0261444817000350

Makopoulou, K., Neville, R. D., Ntoumanis, N., \& Thomas, G. (2019). An investigation into the effects of short-course professional development on teachers' and teaching assistants' self-efficacy. Professional Development in Education, 1-16. https://doi.org/10.1080/19415257.2019.1665572

Mason, J. (2002). Qualitative researching. Sage.

Nowell, L. S., Norris, J. M., White, D. E., \& Moules, N. J. (2017). Thematic Analysis: Striving to Meet the Trustworthiness Criteria. International Journal of Qualitative Methods, 16(1), 1-13. https://doi.org/10.1177/1609406917733847

Ödalen, J., Brommesson, D., Erlingsson, G. Ó., Schaffer, J. K., \& Fogelgren, M. (2019). Teaching university teachers to become better teachers: the effects of pedagogical training courses at six Swedish universities. Higher Education Research Development, 38(2), 339-353. https://doi.org/10.1080/07294360.2018.1512955

O'Dowd, R. (2018). The training and accreditation of teachers for English medium instruction: an overview of practice in European universities. International Journal of Bilingual Education, 21(5), 553-563. https://doi.org/10.1080/13670050.2018.1491945

Oxford, R. L. (1997). Constructivism: Shape-shifting, substance, and teacher education applications. Peabody Journal of Education, 72(1), 35-66. https://doi.org/10.1207/s15327930pje7201_3

Pajares, M. (1992). Teachers' beliefs and educational research: Cleaning up a messy construct. Review of Educational Research, 62, 307-332. https://doi.org/10.3102/00346543062003307

Patton, K., \& Parker, M. (2014). Moving from 'things to do on Monday'to student learning: Physical education professional development facilitators' views of success. Physical Education and Sport Pedagogy, 19(1), 60-75. https://doi.org/10.1080/17408989.2012.726980

Postareff, L., Lindblom-Ylänne, S., \& Nevgi, A. (2007). The effect of pedagogical training on teaching in higher education. Teaching and Teacher Education, 23(5), 557-571. https://doi.org/10.1016/j.tate.2006.11.013

Richardson, V. (1996). The role of attitudes and beliefs in learning to teach. In J. Sulka, T. Buttery, \& E. Guyton (Eds.), Handbook of Research on Teacher Education (pp. 102-119). Macmillan.

Roberts, J. (2016). Language teacher education. Routledge.

Rose, H., \& McKinley, J. (2018). Japan's English-medium instruction initiatives and the globalization of higher education. Higher Education, 75(1), 111-129. https://doi.org/10.1007/s10734-017-0125-1

Seidman, I. (2013). Interviewing as Qualitative Research: A guide for Researchers in Education and the Social Sciences (4th ed.). Teachers College Press.

Tang, S. Y., Wong, A. K., \& Cheng, M. M. (2012). Professional learning in initial teacher education: Vision in the constructivist conception of teaching and learning. Journal of Education for Teaching, 38(4), 435-451. https://doi.org/10.1080/02607476.2012.688549

Terry, G., Hayfield, N., Clarke, V., \& Braun, V. (2017). Thematic analysis. In C. Willig \& W. Stainton Rogers (Eds.), The Sage handbook of qualitative research in psychology (pp. 17-37). Sage.

Tillema, H. H. (1995). Changing the professional knowledge and beliefs of teachers: A training study. Learning and Instruction, 5(4), 291-318. https://doi.org/10.1016/0959-4752(95)00020-8 
Tsui, C. (2018). Teacher Efficacy: A Case Study of Faculty Beliefs in an English-Medium Instruction Teacher Training Program. Taiwan Journal of TESOL, 15(1), 101-128. https://doi.org/10.30397/TJTESOL.201804_15(1).0004

Van de Pol, J., Volman, M., \& Beishuizen, J. (2010). Scaffolding in teacher-student interaction: A decade of research. Educational Psychology Review, 22(3), 271-299. https://doi.org/10.1007/s10648-010-9127-6

Van der Lans, R. M., Van de Grift, W. J. C. M., \& Van Veen, K. (2017). Individual differences in teacher development: An exploration of the applicability of a stage model to assess individual teachers. Learning and Individual Differences, 58, 46-55. https://doi.org/10.1016/j.lindif.2017.07.007

Vygotsky, L. (1978). Mind in Society: Development of Higher Psychological Processes. Harvard University Press.

Wächter, B., \& Maiworm, F. (2014). English-taught programmes in European higher education: The state of play in 2014. ACA Papers on International Cooperation in Education.

Wallace, M. J. (1991). Training Foreign Language Teachers: A Reflective Approach. Cambridge University Press.

Wedell, M., \& Malderez, A. (2013). Understanding Language Classroom Contexts: The Starting Point for Change. Bloomsbury.

Zehetmeier, S., Andreitz, I., Erlacher, W., \& Rauch, F. (2015). Researching the impact of teacher professional development programmes based on action research, constructivism, and systems theory. Educational Action Research, 23(2), 162-177. https://doi.org/10.1080/09650792.2014.997261

\section{Copyrights}

Copyright for this article is retained by the author(s), with first publication rights granted to the journal.

This is an open-access article distributed under the terms and conditions of the Creative Commons Attribution license (http://creativecommons.org/licenses/by/4.0/). 